\title{
Temporal variations of bed load transport rate and the grain size distribution of non-uniform size sediment during a constant flow rates
}

\author{
Yusron Saadi ${ }^{1, *}$, Ida Bagus Giri Putra ${ }^{1}$, and Agus Suroso ${ }^{1}$ \\ ${ }^{1}$ Department of Civil Engineering, University of Mataram, NTB - Indonesia
}

\begin{abstract}
Bedload transport rates at a point using both laboratory and field measurement vary with time, from almost zero to several folds of the mean rate. The need to carry out point measurements over a sufficiently long sampling period is very important to cover inconsistency in the transport rate during a short period of observation. In this experiment the bedload was collected at a slot type sediment trap with ten-minute intervals throughout the tests. The aim was to examine the behaviour of mixed grain size sediment transportation during constant flowrates. Two hydrographs were applied to quantify the transport mode changes caused by an increase in time length as the mixtures were continuously exposed to the flow. It shows that intense bed degradation process occurred within three hours of the tests as indicated by almost identical rates of bedload transport during this period and the diminishing rate in the remaining hours. This reflects that a stable bed was achieved after three hours in which the armouring process was believed to take place. The grain size distribution suggests that the proportion of fine mode was relatively stable and the modal grain size of this mode experienced a similar pattern throughout the tests whilst the coarse mode was inconsistent and varied periodically.
\end{abstract}

\section{Introduction}

The erosion and transport processes of non-uniform sediment are much more complex than those of uniform sediments. Both types of sediment respond very differently to imposed fluid forces. Calculating sediment transport rates of highly non-uniform sediments using a single representative size of the bed material has been recognised as not appropriate. Therefore, in order to predict the response of mixed size sediment to flow, it is necessary to predict the transport rates of individual grain size fractions in the mixtures and then sum them up to obtain the total transport rate.

When there are no significant changes in bed roughness, it can be assumed that the movement of each particle of the sediment bed composed of the finer grains is not greatly affected by the presence of other grains. In coarser beds, the erodibility of the grain is expected to increase due to the grain relative projection above the mean bed and the exposure relative to the upstream grain. In a mixture the mobility of different grain sizes is

\footnotetext{
*Corresponding author: y.saadi@unram.ac.id
} 
strongly equalized by the fact that finer particles are protected by the coarser ones and, therefore, are less subjected to the hydraulic forces than in a uniform-size bed, and that the coarser ones suffer an enhanced exposure to the flow, in comparison to a uniformly sized deposit.

The objective of this study was to examine the behaviour of mixed grain size sediment transportation during constant flow rates. Two hydrographs with different time lengths of constant discharges were applied in order to quantify the changes in the transport mode caused by an increase in the length of time as a mixed grain size sediment bed was exposed to uniform flow rates. It is also expected that transport rate behaviour in correspond to time as well as the change in the composition of surface layer and the level of stability of each grain will be obtained from the experiment.

\section{Literature review}

The existing sediment transport relations are rarely suitable for predicting changes in the size distribution of bed materials in riverbeds undergoing degradation or aggradations [1]. This occurs since those relations only predict the total sediment discharge. Several empirical equations calibrated from different laboratory flume data sets have been proposed by many investigators with the assumption that the sediment is homogeneous and noncohesive $[2,3,4]$. The prediction methods of many existing published sediment transport rate relationships have therefore been developed using data from "uniform" sized sediments to allow the determination of the effects of the 'average' or 'representative' sediment size on transport rates.

Many researchers [1, 5-16] have carried out experiments involving the measurement of bed load transport rates of different fractions in a mixture, and the effect of size gradation. Since the experiments were mostly based on specific conditions, such as the original grain size distribution and the rate and composition of the incoming sediment, it has been difficult to apply the developed relationships to different streams in the field since the complex behaviour of bed load is caused by the existence of variations and different conditions through time [14], its high variability may partially be affected by human activities and temporal variations of hydrological conditions [15] and a wide variety of morphologies exhibited by natural rivers, particularly in mountainous areas [16]. The problem of finding a universal bedload transport equation therefore lies in improving our understanding of the dominant physical factors that control particle movement in natural channels.

Some authors, e.g. Yang [2] and Ackers and White [3] believed that the dominant physical factor in the determination of the total sediment concentration is the unit stream power. Parameters such as water discharge, average velocity, energy slope and shear stress have all been taken to be the dominant independent variables in sediment transport equations. However the rate of transport is very sensitive, and the use of available predictive equations may result in very different answers and in the application produce complexity. Those existing equations are mostly derived under the assumption that there is always a determinate relationship between sediment discharge and a dominant independent variable [2]. Molinas and $\mathrm{Wu}$ [10] proposed that the transport rate functions of Yang [2], Ackers and White [3], and Engelund and Hansen [17] could be used to demonstrate the effect of grain size on the transport of sediment and these functions represent the transport phenomenon adequately. However, for a given flow condition and a range of sediment sizes, considerable scatter exists around the regression equation proposed by Molinas and $\mathrm{Wu}[10]$. The presence of a range of grain sizes introduces many effects into the sediment transport processes. The effects that are of particular importance in mixed grain size beds occur when coarse surface layers develop. The development of these coarser surface layers, 
normally termed "armouring", alters both the surface grain size distribution and the grain surface geometry.

During high flows the supply of transportable sediment might not be uniformly distributed across and along the channel, but will probably be concentrated in local areas. Observations from laboratory and field measurements of sand and gravel transport demonstrate that, even at constant-flow conditions, transport rates at a point vary with time from zero (or near zero) to approximately four times the mean rate [18]. It is therefore very important in field investigation or laboratory experiments to measure the bedload transport rate at the same position over a sufficiently long sampling period in order to cover a distribution of "instantaneous" transport rates which may occur during a short period of observation.

\section{Experimental set up}

The experiments were carried out in a re-circulating glass sided tilting flume similar to the one used in Saadi [19]. The same constant flow rates of $34 \mathrm{l} / \mathrm{s}$ were applied in both tests. A slot type sediment trap located $12.7 \mathrm{~m}$ from the flume inlet was provided to collect the material being transported as bedload. It was positioned in the centre of the flume and equipped with two valves and an interchangeable collection bucket to allow an interrupted collection of bedload samples. This allowed a continuous record of the transport rate and bedload composition to be obtained at discrete time intervals continually throughout each test as a function of time. During the preliminary experiments it was observed that the movement of the bedload was not affected by the operation of the trap so that the pattern of transported bedload was believed to strongly reflect the actual pattern of transport phenomenon in the central section of the flume.

A section of uniformly sized fixed sediment grains was located downstream of the trap to form a static bed. Early observation of this area indicated no grains could have come from the mobile sediment bed. It was therefore concluded that the trap was highly efficient at collecting all the grain sizes in motion. The dimension of the trap is suitable to reliably collect the moving bed material. Preliminary experiments showed that the movement of particles was concentrated in the zone centred along the centreline of the flume. This was reflected by the existence of a valley-formed bed along the centreline of the flume where the average width of the valleys matched the width of the bedload trap.

Table 1. Summary of experimental set up.

\begin{tabular}{|c|c|c|c|c|}
\hline \multirow{2}{*}{$\begin{array}{c}\text { Experiment } \\
\text { number }\end{array}$} & \multirow{2}{*}{$\begin{array}{c}\text { Discharge } \\
(\mathbf{l} / \mathbf{s})\end{array}$} & $\begin{array}{c}\text { Flow } \\
\text { duration } \\
\text { (hours) }\end{array}$ & \multicolumn{2}{|c|}{ Sediment characteristic } \\
\cline { 4 - 5 } & 34 & 3 & $\tau_{\mathrm{g}}$ & $\mathrm{d}_{50}(\mathrm{~mm})$ \\
\hline Test 1 & 34.42 & 5.19 \\
\hline Test 2 & 34 & 6 & 3.42 & 5.19 \\
\hline
\end{tabular}

The sediment mixture used in the experiment was manufactured from three different grain size sediments to represent the natural sediment mixtures in many rivers (see Table 1). The mixtures have two modes, with the fine mode composed of three dominant grain sizes in the finer materials $(0.25,0.355$ and $0.5 \mathrm{~mm})$, while the coarse mode covered three dominant grain sizes in the coarser group $(4.0,5.6$ and $8.0 \mathrm{~mm})$. The geometric standard deviation of the mixture $\left(\tau_{\mathrm{g}}\right)$ is 3.42 with $d_{50}$ equal to $5.19 \mathrm{~mm}$. This bimodal mixture was spread along the flume before the hydrograph was applied. During the tests no sediment was fed into the flume at the upstream boundary. The transported bedload was collected 
throughout the tests at 10-minute intervals and sieved to show the changes in the amounts transported in each mode.

\section{Results and discussions}

The observations indicate significant and rapid changes in the bedload transport rates during the initial hours of constant flow rates. Figure 1 shows that the Test 1 bed materials were highly mobile during the first 60 minutes with an average transport rate of 0.40 $\mathrm{gr} / \mathrm{s} / \mathrm{m}$. This suggests that the transport processes involve sporadic release of material as bed adjustments took place. The movement of particles was very active reflecting the progressive development of the bed surface caused by a high constant discharge. The average transport rate reduced to $0.18 \mathrm{gr} / \mathrm{s} / \mathrm{m}$ during the second hour, or to less than half of the initial rate. As the armouring process continued the transport rate continued to decrease, but at a slower rate reflecting the diminishing supply of dislodgeable grains. This was indicated by the almost constant transport rate during the last 60 minutes at $0.15 \mathrm{gr} / \mathrm{s} / \mathrm{m}$.

Similar to that in Test 1, there was a significant change in the bedload transport rate during the initial stages of Test 2. During the first hour the bedload transport rate was 0.38 $\mathrm{gr} / \mathrm{s} / \mathrm{m}$. The rate dropped rapidly within the course of one hour to a rate of $0.19 \mathrm{gr} / \mathrm{s} / \mathrm{m}$, half of the bedload production of the preceding hour. In the next hour the rate fluctuated but continued to decrease with a rate of $0.13 \mathrm{gr} / \mathrm{s} / \mathrm{m}$. Another drop took place in the fourth hour of the test. At this stage the bedload transport rate decreased to more than $30 \%$ of the previous hour to $0.09 \mathrm{gr} / \mathrm{s} / \mathrm{m}$. Figure 1 shows that after this period the bedload transport rate was low and almost constant during the remaining hours with a rate of $0.07 \mathrm{gr} / \mathrm{s} / \mathrm{m}$ both in the fifth and the sixth hours respectively. This pattern of transport suggests that the bed was highly mobile during the first 180 minutes involving a significant release of material from bed during the first 60 minutes of elapsed time. The re-arrangement of the bed is the result of sediment movement. As the armouring process continued the transport rate continued to decrease. It is believed that after 180 minutes, the bed started to develop differently. This is reflected in the slower and almost constant rate of bedload transportation.

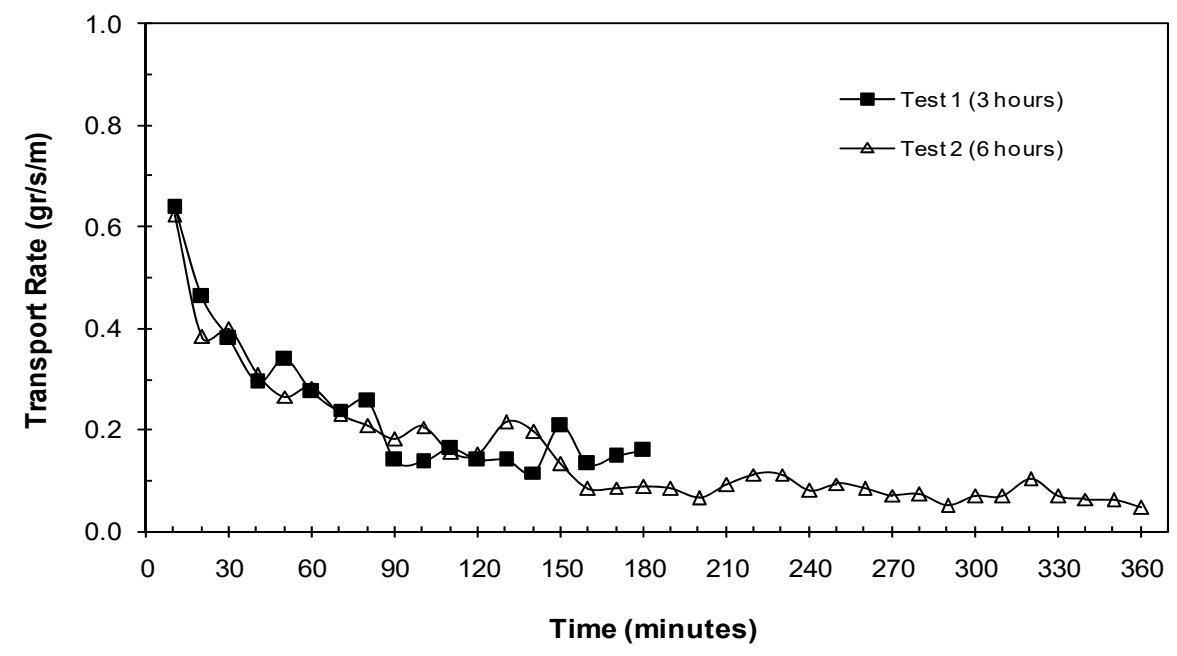

Fig. 1. Time variation of bedload transport rate during the experiments.

The application of a relatively high constant discharge to freshly laid bimodal sediment beds has a different effect on the fine and the coarse modes of transported sediment. During 
Test 1, the bedload composition shows systematic changes. Observations of grain distribution curves of the bedload indicate that the degradation phase occurred during the initial stages (Figure 2). In terms of modal grain size, the fine mode experienced a similar pattern of transport throughout the 3 hours whilst the coarse mode shows variations. The grain size of $0.355 \mathrm{~mm}$ was dominant in the fine mode for the whole duration of the test.

In the coarse mode, the grain size of $4 \mathrm{~mm}$ was dominant during the very first part of the test, i.e. $10-40$ minutes of elapsed time. These grains were thought to represent very loose or exposed grains, whose lack of stability had been caused by the mechanical scraper originally used to form the bed. Once these grains had largely been transported, larger grains of $5.6 \mathrm{~mm}$ become more exposed. The modal grain size in the coarse mode therefore increased. At an elapsed time of 90 minutes the proportion of $5.6 \mathrm{~mm}$ grains with sufficient exposure declined so much that the modal grain size reduced to $4 \mathrm{~mm}$. This remained constant until 130 minutes elapsed when the coarse modal grain size varied from $5.6 \mathrm{~mm}$ to $4 \mathrm{~mm}$ periodically. The inconsistency in the coarse mode was believed to indicate the increasing exposure of larger grains as a result of decreasing amounts of finer grains left on the bed. The active depth of the bed had been found to be less than half of the largest grain size present. After the test the average bed surface measured by the vernier depth gauge had reduced by $4.3 \mathrm{~mm}$. This decrease is approximately half the size of the largest grain size used in the sediment mixtures. A layer in the prediction of sediment available for transport was assumed using the two-layer active depth available for transport in a mixing layer as suggested by Willetts et al. [20]. In this case the active depth based on the present of largest grain $d_{100}$ where each layer is equal in thickness to half of the largest grain is coincide with the actual decreasing bed surface level. The mixing layer contains 40.90 kilograms of sediment mixtures available for transport and 496.93 grams were transported during the course of 3 hours. The composition of the total transported bedload was calculated from laboratory observations so that the bed surface composition at the end of the Test 1 could be estimated. As seen in Table 2, the percentage of the fine and coarse modes transported at the end of Test 1 are $38 \%$ and $40 \%$ respectively. It is evident that the grain sizes of 0.355 $\mathrm{mm}$ and $4.0 \mathrm{~mm}$ contributed quite significantly to the transported bedload so that the estimated composition of these sizes left on the bed at the end of the test are less than the original composition of the surface layer.

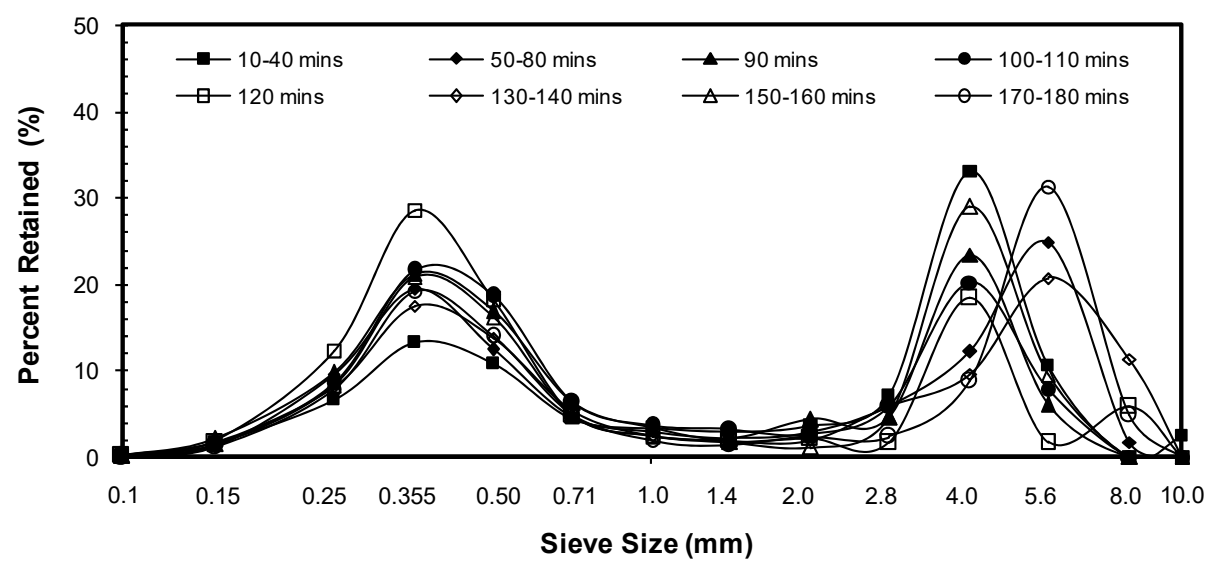

Fig. 2. Grain size distribution of transported bedload for Test 1. 
Table 2. Summary of the average fractional composition of transported bedload.

\begin{tabular}{|c|c|c|c|c|c|c|}
\hline \multirow{2}{*}{$\begin{array}{c}\text { Sieve size } \\
(\mathbf{m m})\end{array}$} & \multicolumn{2}{|c|}{$\begin{array}{c}\text { Original composition of } \\
\text { surface layer (\%) }\end{array}$} & \multicolumn{2}{c|}{$\begin{array}{c}\text { Fractional transported } \\
\text { bedload (\%) }\end{array}$} & \multicolumn{2}{c|}{$\begin{array}{c}\text { Estimated composition } \\
\text { of surface layer (\%) }\end{array}$} \\
\cline { 2 - 7 } & Test 1 & Test 2 & Test 1 & Test 2 & Test 1 & Test 2 \\
\hline 10.0 & 1.730 & 1.730 & 1.023 & 0.000 & 1.739 & 1.757 \\
\hline 8.0 & 8.570 & 8.570 & 1.634 & 0.830 & 8.655 & 8.693 \\
\hline 5.6 & 34.660 & 34.660 & 15.594 & 16.212 & 34.894 & 34.952 \\
\hline 4.0 & 19.600 & 19.600 & 22.676 & 14.238 & 19.562 & 19.685 \\
\hline 2.8 & 6.860 & 6.860 & 5.826 & 2.518 & 6.873 & 6.929 \\
\hline 2.0 & 3.530 & 3.530 & 2.925 & 1.489 & 3.537 & 3.562 \\
\hline 1.4 & 2.510 & 2.510 & 2.422 & 1.728 & 2.511 & 2.522 \\
\hline 1.0 & 1.850 & 1.850 & 2.975 & 2.628 & 1.836 & 1.838 \\
\hline 0.71 & 2.680 & 2.680 & 4.806 & 6.098 & 2.654 & 2.626 \\
\hline 0.5 & 6.840 & 6.840 & 13.022 & 18.743 & 6.764 & 6.652 \\
\hline 0.355 & 7.420 & 7.420 & 17.387 & 23.991 & 7.297 & 7.158 \\
\hline 0.25 & 2.710 & 2.710 & 8.084 & 9.780 & 2.644 & 2.598 \\
\hline 0.15 & 0.940 & 0.940 & 1.527 & 1.612 & 0.933 & 0.929 \\
\hline receiver & 0.100 & 0.100 & 0.099 & 0.132 & 0.100 & 0.099 \\
\hline
\end{tabular}

Looking at Test 1 overall, three stages of activities have been identified. The first, which is relatively short (time elapsed 10-40 minutes), was controlled by the initial artificial condition of the bed. The second stage (time elapsed 40-120 minutes) was characterized by increasing amounts of fine material being moved and the coarse modal grain size moving from $5.6 \mathrm{~mm}$ to $4.0 \mathrm{~mm}$. In the third stage (time elapsed 120-180 minutes), the proportion of the fine grains started to reduce. The proportion of the coarse mode increased and its behaviour became more erratic, with the coarse modal grain size alternating between $5.6 \mathrm{~mm}$ and $4.0 \mathrm{~mm}$.

The composition of the transported bedload during the initial stages of Test 2 was dominated by the fine mode. As can be seen from Figure 3, more sediment was transported in the fine mode than in the coarse mode throughout the test. In the last hour the rate of this mode reduced as the availability of this material left on the bed decreased. However, the contribution of this mode was still higher than the coarse mode. The fine mode also shows a similar pattern in the grain size distribution with the modal size of fine grains being 0.355 $\mathrm{mm}$ for the whole duration of the test. More interesting features are shown by the changes in the coarse mode. As the test progressed, the modal size of coarse grain shifts to the right from a grain size of $4.0 \mathrm{~mm}$ to larger grain sizes.

This suggests that the level of exposure of the larger grains increased with time. This leads to the flow being able to transport the larger grains. Although the percentage of finer grain transported during the test was dominant, this is not an indication that the coarse mode was more stable. It is the reflection of the ability of the flow to continuously remove the finer grain for the whole duration of the test. 


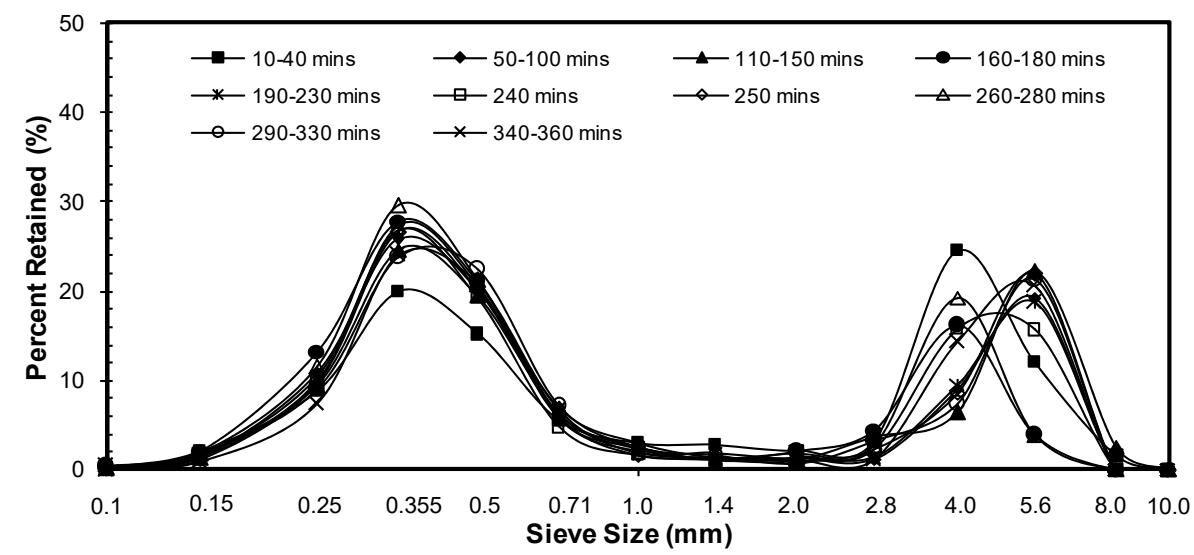

Fig. 3. Grain size distribution curve of transported bedload for Test 2.

The surface grain size distribution was estimated in a similar manner as in Test 1. From the original mixing layer available for transport, 637.60 grams or $1.6 \%$ were transported. More than half, i.e. 478.78 grams, were transported during the first 3 hours of Test 2 . This amount is very close to the transported bedload in the equivalent period of Test 1 . Table 2 shows that grains in the fine mode contributed more than grains in the coarse mode for the transport rate as suggested by the distribution curve in Figure 3. It appears that after 40 minutes the proportion of the fine mode was relatively stable whereas the modal grain size of the coarse mode started to fluctuate. The percentage of fine mode in transported bedload is $52 \%$ whilst the coarse mode, this is $31 \%$. This resulted in the formation of a coarser surface layer than the original bed, which means the bed surface had coarsened during the Test 2 (see Table 2).

Normally when a constant flow discharge is applied, the transport rate with no upstream sediment feed is a function of time. The transport rate is expected to decrease rapidly and then remained at a low value. In this case the amount of bedload may be higher for the longer duration of experiments but this is not due to any increase in the transport rate: this is because after a set time the bed had reached an armoured stable condition and very low transport rates existed. It is clearly shown by Table 3 that the total amount of bedload transported in Test 2 increased only less than one third in comparison to that in Test 1 . It is noticeable that after 3 hours of constant flow rate the bed was more stable and the rate of transport reduced in the remaining hours.

Table 3. Summary of transported bedload for the experiments.

\begin{tabular}{|c|c|c|c|c|c|c|}
\hline \multirow{2}{*}{$\begin{array}{c}\text { Experiment } \\
\text { No. }\end{array}$} & \multicolumn{2}{|c|}{ Bedload transport } & \multicolumn{3}{c|}{ Mass and proportion of mode } \\
\cline { 2 - 7 } & $\begin{array}{c}\text { Mass } \\
\text { (gr) }\end{array}$ & $\begin{array}{c}\text { Rate } \\
(\mathbf{g r} / \mathbf{s} / \mathbf{m})\end{array}$ & \multicolumn{2}{|c|}{ Fine mode } & \multicolumn{2}{c|}{ Coarse mode } \\
\cline { 4 - 7 } & & $\mathbf{( g r )}$ & $\mathbf{( \% )}$ & $\mathbf{( g r )}$ & $\mathbf{( \% )}$ \\
\hline Test 1 (3 hours) & 496.93 & 0.24 & 191.28 & 38.49 & 198.30 & 39.91 \\
\hline Test 2 (6 hours) & 637.60 & 0.16 & 334.83 & 52.51 & 199.44 & 31.28 \\
- First 3 hours & 478.78 & 0.23 & 244.66 & 38.37 & 154.04 & 24.16 \\
- Last 3 hours & 158.82 & 0.08 & 90.16 & 14.14 & 45.34 & 7.12 \\
\hline
\end{tabular}

Observation of the temporal pattern in transport rates suggested that the armoured stable bed condition was achieved between elapsed time of 3 and 6 hours as the transport rate dropped dramatically after 3 hours after exposure to the flow. It is believed that the process of grain size sorting also took place within this period leading to a formation of specific 
grain size distribution in the bed surface. In the last 3 hours of Test 2 a small bedload production was experienced. During this period only 90.16 grams of grains in fine mode were transported. This is a more than $63 \%$ decrease compared to that transported during the first 3 hours of the test (244.66 grams). The grains in the fine mode were better sheltered after 3 hours so that the rates dropped in the following hours. The grains in the coarse mode were also thought to have reached a stable condition. This is indicated by the relatively constant amount transported during the second period of Test 2 . Only $7.12 \%$ was transported in the last 3 hours, or a decrease of more than $70 \%$ from the proportion produced in the first 3 hours of the test.

\section{Conclusions and recommendations}

\subsection{Conclusions}

The experiments enable some conclusions to be drawn as follows:

1. A considerable amount of grains in both the fine and the coarse mode were transported during the initial stages of the experiments. The amount of transported bedload during the first three hours is almost similar regardless of the total duration of the experiment. Intense degradational processes occurred during these periods, with the proportion of grains in the fine mode being more dominant than grains in the coarse mode.

2. The stable armoured bed had been achieved after three hours of flow exposure. This was clearly indicated by a considerable decrease in bedload transport during the second period of three hours in which a very low and constant transport rate took place. The grains in the fine mode were better sheltered after three hours so that the rates dropped in the remaining hours. The diminishing supply reflects the bed stabilization as the armouring process continued.

3. The coarsening process of the bed surface occurred during the tests as indicated by the domination of grains in the fine mode in the total transported bedload. At the end of the tests the estimated compositions of the surface layer were coarser than of the original composition of the bed surface.

4. The grain size distribution analysis of transported bedload at all elapsed times suggest that the proportion of the fine mode was relatively stable and the modal grain size of this mode experienced a similar pattern throughout the tests whilst the coarse mode was inconsistent and varied periodically.

\subsection{Recommendations}

In terms of transport rate, stages of activity have been identified from the experiment where the transport processes occurred intensely during the initial hours. Although in the last 3 hours the diminishing rate of transport is highly noticeable, there is no guarantee that no potential break up will be experienced by the bed beyond this period. Experiments with longer durations of constant flow rates will hopefully provide information on whether the bed stability increases to some extent as the time progresses, or may be destabilised and contributes to a considerable transport rate after long and continuous exposure to the flow.

\section{References}

1. F. Karim, J. Hyd. Eng., 124, 6, 597-604 (1998)

2. C.T. Yang, J. Hyd. Div., 99, 10, 1679-1704 (1973) 
3. P. Ackers, W.R. White, J. Hyd. Div., 99, 11, 2041-2060 (1973)

4. L.C. van Rijn, J. Hyd. Div., 110, 1733-1754 (1984)

5. P.C. Klingeman, W.W. Emmett, Gravel Bed Rivers, eds. R.D. Hey, J.C. Bathurst, and C.R. Thorne, 141-179 (1982)

6. R.L. Misri, R.J. Garde, K.G. Ranga Raju, J. Hyd. Eng., 110, 3, 312-328 (1984)

7. I. Reid, L.E. Frostick, Recent Development in Fluvial Sedimentology, eds. F.G. Ethridge, R.M. Flores and M.D. Harvey, 13-19 (1987)

8. P.R. Wilcock, J.B. Southard, Water Resour. Res., 25, 7, 1629-1641 (1989)

9. A.F. Barta, P.R. Wilcock, C.C.C. Shea, Proc. Nat. Con. Hyd. Eng., 2, 780-784 (1994)

10. A. Molinas, B. Wu, J. Hyd. Eng., 124, 8, 786-793 (1998)

11. A.B. Shvidchenko, Z.D. Kopaliani, J. Hyd. Eng., 124, 8, 779-785 (1998)

12. Y. Saadi, S.J. Tait, Proc. 3rd Int. Symp. Environ. Hyd., Manuscript 00124 (2001)

13. K. Goshal, B.S. Mazumder, B. Purkait, Sedimentary Geology, 223, 1-14 (2010)

14. S.H. Sadeghi, H. Kheirfam, Clean-Soil Air Water, 43, 10, 1357-1442 (2015)

15. N. Lana-Renault, D. Regues, Catena, 71, 155-163 (2007)

16. M.A. Elgueta-Astaburuaga, M.A. Hassan, Water Resour. Res., 53, 1-16 (2016)

17. F. Engelund, E. Hansen, A Monograph on Sediment Transport in Alluvial Streams, (Teknisk Forlag, Copenhagen, 1967)

18. D.W. Hubbell, Sediment Transport in Gravel Be Rivers, eds. C.R. Thorne, J.C. Bathurst, R.D. Hey, 89-118 (1987)

19. Y. Saadi, J. Civ. Eng. Dimension, 10, 2, 89-98 (2008)

20. B.B. Willett, J.K. Maizels, J. Florence, Proc. Inst. Civ. Engs., Part I, 82, 799-814 (1987) 